\title{
Dermo-Hipodermites Bacterianas Agudas Não Necrotizantes: Erisipela e Celulite Infeciosa
}

\section{Non-Necrotizing Acute Dermo-Hypodermal Infections: Erysipela and Infectious Cellulitis}

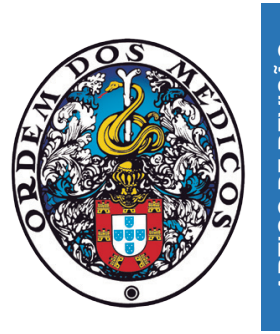

\author{
Maria Alexandra RODRIGUES ${ }^{1}$, Mónica CAETANO $\otimes^{1,2}$, Isabel AMORIM ${ }^{1}$, Manuela SELORES 1,2
}

Acta Med Port 2021 Mar;34(3):217-228 $\cdot$ https://doi.org/10.20344/amp.12642

\section{RESUMO}

As dermo-hipodermites bacterianas agudas não necrotizantes são processos infeciosos que incluem a erisipela e a celulite infeciosa, e são geralmente causadas por estreptococos $\beta$-hemolíticos do grupo A. Em mais de $80 \%$ dos casos situam-se nos membros inferiores e são fatores predisponentes a existência de solução de continuidade na pele, o linfedema crónico e a obesidade. O seu diagnóstico é essencialmente clínico e o quadro típico baseia-se na presença de placa inflamatória associada a febre, linfangite, adenopatia e leucocitose. Os exames bacteriológicos têm baixa sensibilidade ou positividade tardia. Nos casos atípicos é importante o diagnóstico diferencial com a fasceíte necrotizante e a trombose venosa profunda. A flucloxacilina ou a cefradina são os fármacos de primeira linha. A recidiva constitui a complicação mais frequente, sendo fundamental o correto tratamento dos fatores de risco.

Palavras-chave: Celulite/diagnóstico; Celulite/prevenção e controlo; Celulite/tratamento; Erisipela/diagnóstico; Erisipela/prevenção e controlo; Erisipela/tratamento; Infecções dos Tecidos Moles/diagnóstico; Infecções dos Tecidos Moles/prevenção e controlo; Infecções dos Tecidos Moles/tratamento

\section{ABSTRACT}

Non-necrotizing acute dermo-hypodermal infections are infectious processes that include erysipela and infectious cellulitis, and are mainly caused by group A $\beta$-haemolytic streptococcus. The lower limbs are affected in more than $80 \%$ of cases and the risk factors are disruption of cutaneous barrier, lymphoedema and obesity. Diagnosis is clinical and in a typical setting we observe an acute inflammatory plaque with fever, lymphangitis, adenopathy and leucocytosis. Bacteriology is usually not helpful because of low sensitivity or delayed positivity. In case of atypical presentations, erysipela must be distinguished from necrotizing fasciitis and acute vein thrombosis. Flucloxacillin and cefradine remain the first line of treatment. Recurrence is the main complication, so correct treatment of the risk factors is crucial.

Keywords: Cellulitis/diagnosis; Cellulitis/prevention and control; Cellulitis/therapy; Erysipelas/diagnosis; Erysipelas/prevention and control; Erysipelas/therapy Soft Tissue Infections/diagnosis; Soft Tissue Infections/therapy

\section{DEFINIÇÃO, ASPECTOS HISTÓRICOS E TERMINOLOGIA}

As dermo-hipodermites bacterianas agudas são processos infeciosos que podem ser divididos em dermo-hipodermites bacterianas agudas não necrotizantes (DHBANN) - a erisipela e a celulite infeciosa - e dermo-hipodermites bacterianas agudas necrotizantes (DHBAN) - a fasceite necrotizante (Tabela 1). ${ }^{1}$ A distinção tem importantes implicações na abordagem e no prognóstico, uma vez que a fasceíte necrotizante (com uma mortalidade de cerca de $30 \%$ ) para além de antibioterapia adequada necessita de tratamento cirúrgico o mais precocemente possível. A presente revisão tem como âmbito as DHBANN, pela sua frequência e por permanecerem um desafio diagnóstico e terapêutico.

As DHBANN apresentam uma etiologia infeciosa previsível, sendo causadas maioritariamente por cocos gram-positivos (estreptococos e estafilococos). Apesar da resolução do episódio infecioso, a recidiva é frequente. ${ }^{1,2}$ Mesmo na era pré-antibiótica, verificava-se geralmente uma evolução espontânea para a cura em uma a três semanas, associando-se, porém, a importantes sequelas e significativa taxa de mortalidade. $\mathrm{O}$ advento da antibioterapia permitiu o quase desaparecimento de casos fatais, pelo que atualmente se orientam todos os esforços o controlo efetivo dos fatores de risco, responsáveis pela elevada taxa de recidiva, notável morbilidade e considerável dispêndio de recursos económicos e sociais associados a esta infeção.

$\mathrm{Na}$ literatura, sobretudo a anglo-saxónica, é frequente o uso indiscriminado dos termos erisipela e celulite para classificar diferentes processos inflamatórios que afetam a pele. Classicamente, o primeiro sugere uma localização mais superficial e uma etiologia exclusivamente infeciosa (bacteriana). O segundo aponta para a localização no tecido celular subcutâneo, e é utilizado para classificar as diversas situações inflamatórias dos tecidos moles, independentemente da sua etiologia: desde a inestética 'celulite' às celulites infeciosas (erisipela, fasceíte necrotizante, celulite estreptocócica peri-anal), às celulites assépticas (celulite eosinofílica de Wells, celulite dissecante do couro cabeludo) e a entidades ambíguas como a celulite de estase venosa e/ou linfática. No contexto específico das infeções bacterianas da pele, o termo celulite tem vindo a ser abandonado pelos dermatologistas a favor da designação 'infeção dermo-hipodérmica' ou dermohipodermite.

1. Serviço de Dermatovenereologia. Centro Hospitalar e Universitário do Porto. Porto. Portugal.

2. Departamento de Dermatovenereologia. Instituto de Ciências Biomédicas Abel Salazar. Porto. Portugal.

$\square$ Autor correspondente: Mónica Caetano. caetanomonica@netcabo.pt

Recebido: 03 de agosto de 2019 - Aceite: 24 de janeiro de 2020 - Online issue published: 01 de março de 2021

Copyright $\odot$ Ordem dos Médicos 2021 
Tabela 1 - Dermo-hipodermites bacterianas agudas (DHBA) - classificação

\begin{tabular}{ll}
\hline $\begin{array}{l}\text { Dermo-hipodermites bacterianas agudas não necrotizantes } \\
\text { (DHBANN) }\end{array}$ & $\begin{array}{l}\text { Dermo-hipodermites bacterianas agudas necrotizantes } \\
\text { (DHBAN) }\end{array}$ \\
\hline Início súbito (febre, arrepios) & Igual \\
Lesões com bordos bem definidos & Lesões mal delimitadas \\
Dor & $\begin{array}{l}\text { Inicialmente: Dor desproporcional aos achados cutâneos e que } \\
\text { ultrapassa os limites da lesão; Tardio: Hipoestesia }\end{array}$ \\
Estase linfática e linfangite & Necrose e tromboses venosas \\
Antibioterapia & Antibioterapia e Cirurgia \\
Mortalidade $0,5 \%$ & Mortalidade $30,0 \%$
\end{tabular}

Tabela 2 - Dermo-hipodermites bacterianas agudas não necrotizantes (DHBANN)

\begin{tabular}{l} 
Erisipela (DHBANN típica) \\
\hline Infeção dérmica \\
Lesões de bordos bem definidos \\
Linfedema \\
Evolução curta \\
Complicações locais raras
\end{tabular}

As DHBANN incluem a erisipela e a celulite infeciosa. $O$ quadro clássico de erisipela (DHBANN típica) caracteriza-se por um início súbito com febre e arrepios, seguido pelo aparecimento de placa eritematosa, edematosa, quente e dolorosa, de limites bem definidos e geralmente localizada num membro inferior. A celulite infeciosa (DHBANN atípica) é geralmente associada a um quadro clínico mais inespecífico, com ou sem febre, com placa eritematosa e quente, de limites mal definidos e dor variável (Tabela 2 ).

Historicamente, acreditava-se que a distinção entre erisipela e celulite infeciosa teria importância na abordagem terapêutica. A primeira seria uma entidade unicamente causada por estreptococos do grupo A, enquanto que a celulite infeciosa poderia também ter etiologia estafilocócica (com as respetivas implicações terapêuticas). No entanto, sucessivos estudos etiológicos vieram a demonstrar que em ambas o estreptococo do grupo A (Streptococcus pyogenes) é o agente etiológico mais frequente, e que o Staphylococcus aureus é responsável por cerca de $15 \%$ dos casos. ${ }^{3-5}$ No mesmo sentido, a distinção baseada unicamente nos critérios clínicos (Tabela 2 ) nem sempre é possível, pelo que se dá hoje preferência a um termo que inclua as duas entidades - DHBANN. ${ }^{6}$

Importa reforçar que o diagnóstico das DHBANN é clínico, assentando maioritariamente na história e exame físico, pelo que um dos grandes desafios é o diagnóstico diferencial. Por este motivo, o conhecimento das características do quadro típico de uma DHBANN (tal como a apresentação clássica da erisipela) mantém utilidade clínica, pois permite um diagnóstico com elevado grau de probabilidade, evitando a realização de exames e procedimentos desnecessários, e permitindo a instituição do tratamento empírico o mais precocemente possível. Nos casos de DHBANN com apresentações atípicas importa equacionar outras entidades clínicas, uma vez que entre os diagnósticos diferenciais se encontram patologias associadas a morbilidade e mortalidade elevadas, tais como a fasceíte necrotizante e a trombose venosa profunda. ${ }^{7}$
Celulite infeciosa (DHBANN atípica)

Infeção dermo-hipodérmica

Lesões mal delimitadas

Envolvimento linfático inconstante

Evolução prolongada

Complicações locais frequentes (por exemplo abcesso)

\section{EPIDEMIOLOGIA}

As DHBANN são uma patologia frequente. A taxa de incidência varia entre $0,2 / 1000$ a 24,6/1000 pessoas-anos em diferentes populações. Afetam o membro inferior em cerca de $80 \%$ dos casos, podendo também ocorrer nos membros superiores, face, e tronco. ${ }^{8}$

As DHBANN do membro superior estão associadas a utilizadores de drogas intravenosas e mulheres submetidas a esvaziamento ganglionar axilar por neoplasia da mama (com uma incidência que pode atingir os $24 \%$ ). $^{8,9}$

\section{BACTERIOLOGIA}

Tal como em qualquer processo de natureza infeciosa, o isolamento do agente responsável é o argumento definitivo para o diagnóstico. No entanto, nas DHBANN a contribuição diagnóstica da bacteriologia é limitada pela sua fraca sensibilidade e ausência de resultados em tempo útil. ${ }^{10}$ Este facto pode ser explicado, em parte, porque a carga bacteriana é baixa, apesar da resposta inflamatória intensa associada. ${ }^{11,12}$

Os agentes etiológicos mais frequentes das DHBANN são constituintes do microbiota normal da pele. Normalmente, são causadas por estreptococos grupo A (raramente grupo B, C ou G), ${ }^{5}$ embora a infeção por Staphylococcus aureus também seja possível $(15 \%),{ }^{3-5}$ sendo mais frequente após cirurgia, trauma penetrante ou feridas. ${ }^{13-15}$ Os resultados de um estudo realizado em 42 doentes com DHBANN através de cultura e imunofluorescência direta de biópsias cutâneas estão descritos na Tabela $3 .^{16}$

Tabela 3 - Agentes etiológicos das dermo-hipodermites bacterianas agudas não necrotizantes (DHBANN) ${ }^{17}$

\begin{tabular}{cc}
\hline Infeção estreptocócica & $88,0 \%$ \\
- Streptococcus Grupo A & $57,0 \%$ \\
- Streptococcus Grupo G & $11,0 \%$ \\
- Streptococcus Grupo D & $3,0 \%$ \\
Staphylococcus aureus & $7,1 \%$ \\
\hline
\end{tabular}


Tabela 4 - Agentes etiológicos de dermo-hipodermites bacterianas agudas não necrotizantes (DHBANN) atípicas

\begin{tabular}{ll} 
Úlceras crónicas em diabéticos & Anaeróbios e bactérias gram-negativas \\
Antecedentes de dissecção de nódulo linfático pélvico & Streptococcus agalactiae \\
Imunossupressão & Bactérias gram-negativas, Streptococcus pneumoniae \\
Doença hepática crónica & \\
Síndrome nefrótico & \\
Mordeduras de cão e gato & Pasteurella multocida e Capnocytophaga canimorsus \\
Mordeduras de humano & Eikenella corrodens \\
Climas tropicais, exposição a água salgada & Vibrio vulnificus \\
Exposição a água doce & Espécies de Aeromonas \\
Exposição a carne ou peixe cru & Erysipelothrix rhusiopathiae \\
\hline
\end{tabular}

A Pseudomonas aeruginosa também se encontra associada a infeções de tecidos moles, sobretudo em populações vulneráveis (com imunossupressão ou antibioterapia de largo espectro prévia) ou em expostos a jacuzzis e esponjas contaminadas. ${ }^{17,18} \mathrm{Em}$ doentes com baixa reserva fisiológica pode conduzir a choque séptico e morte. ${ }^{19}$

Agentes etiológicos incomuns incluem Streptococcus pneumoniae, Haemophilus influenzae, bacilos gram negativos e anaeróbios. Geralmente, encontram-se associados a mecanismos de lesão específicos (ferida, queimadura) ou comorbilidades (diabetes, neoplasia, malnutrição). ${ }^{19-21}$ A exposição a água salgada associa-se a infeção por Vibrio vulnificus, enquanto que a água doce está associada à $A e-$ romonas hydrophila. ${ }^{22}$ Pasteurella multocida e Capnocytophaga canimorsus estão associadas a mordeduras de cães e gatos, enquanto que a Eikenella corrodens se associa a mordeduras humanas ${ }^{6}$ (Tabela 4 ).

\section{FATORES DE RISCO}

As DHBANN associam-se a vários fatores de risco locais e sistémicos que, quando presentes, elevam a probabilidade do diagnóstico. A sua correção, por outro lado, diminui o risco de recidiva.

O linfedema crónico e a existência de uma porta de entrada (intertrigo interdigital fúngico, úlcera crónica, lesão traumática) são os mais importantes e muito frequentes nas DHBANN do membro inferior. Em quase $80 \%$ dos doentes é possível identificar uma porta de entrada, que em metade dos casos é uma infeção fúngica superficial (tinea pedis). ${ }^{23}$ Os espaços interdigitais estão frequentemente colonizados por estreptococos e Staphylococcus aureus, ${ }^{24,25}$ explicando o acesso às camadas mais profundas da pele e desenvolvimento de infeção.

Entre os fatores sistémicos, destaca-se a obesidade. ${ }^{26}$ De referir também a doença vascular periférica, assim como cirurgias locais prévias com compromisso da drenagem linfática. ${ }^{22} \mathrm{O}$ aumento do risco com imunossupressão, álcool, diabetes e tabaco não foi verificado em séries de casos. ${ }^{26}$

Nas DHBANN da face a infeção tem diversas origens, tais como a presença de um abcesso/ furúnculo manipulado ou sobreinfeção bacteriana de lesões herpéticas, eczema, piercings e, nos casos específicos de localização peri-orbitária ou orbitária, a existência de ferida traumática, infeção do trato respiratório superior ou, mais raramente, a bacteriemia. $^{27,28}$

\section{QUADRO CLÍNICO}

As DHBANN têm uma apresentação aguda, com sinais

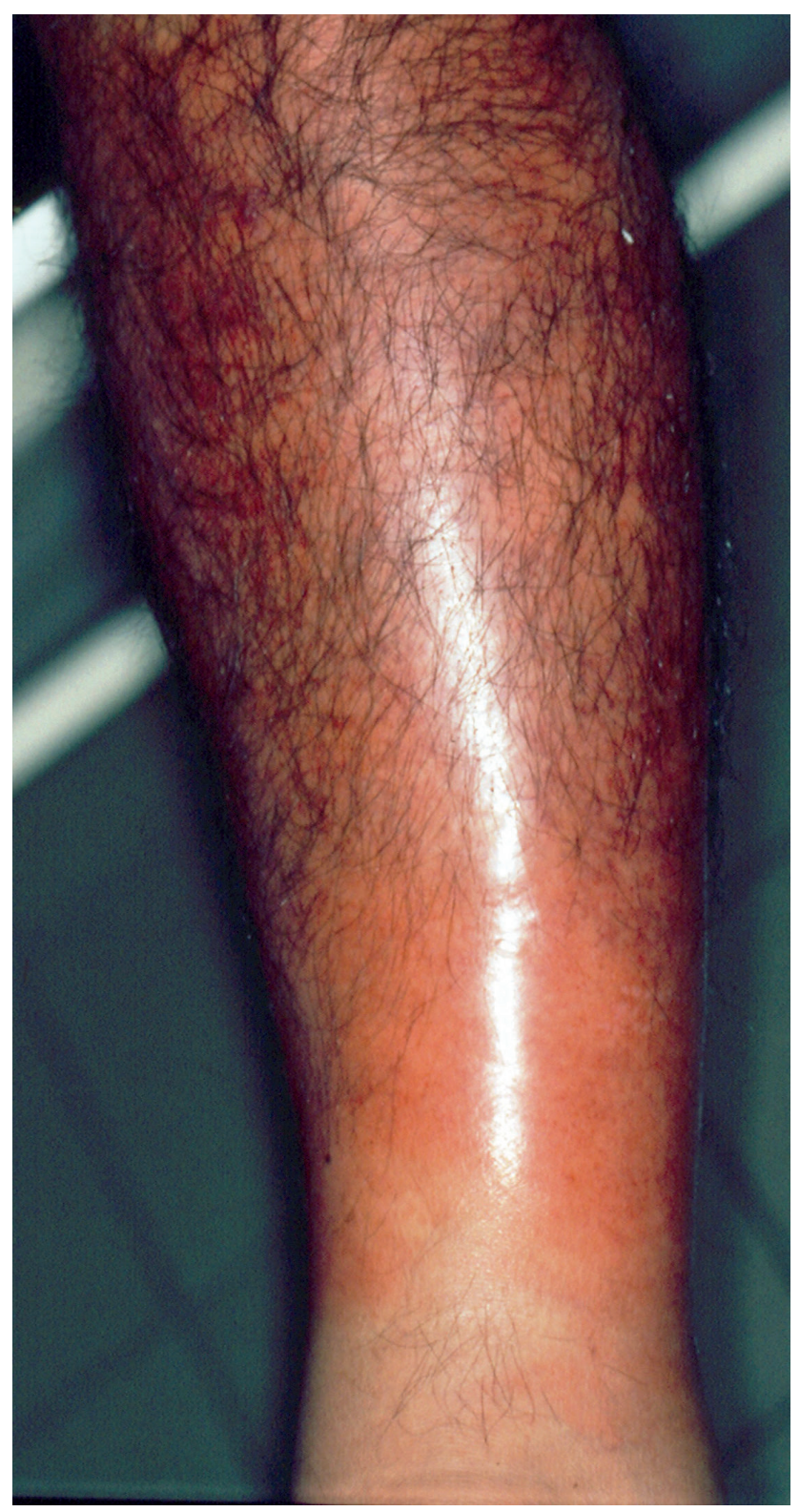

Figura 1 - Erisipela do membro inferior 


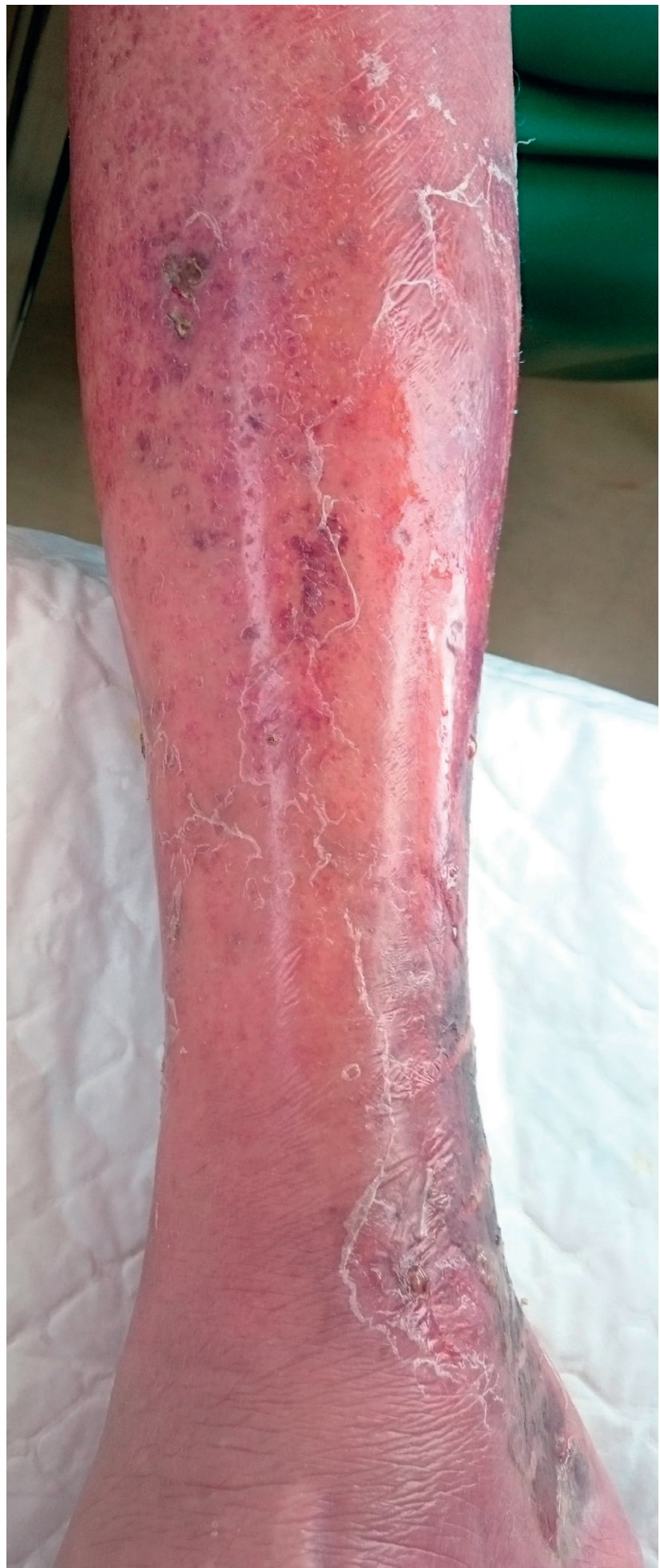

Figura 2 - Erisipela bolhosa do membro inferior

inflamatórios locais, mais frequentemente no membro inferior e quase invariavelmente unilaterais. Geralmente, o estado geral está preservado.

A apresentação típica de DHBANN é o quadro clássico de erisipela, que se caracteriza por um início súbito com febre $\left(38,5^{\circ}-40^{\circ} \mathrm{C}\right)$ e arrepios, seguido pelo aparecimento de placa eritematosa (vermelha viva), edematosa, quente e dolorosa, de limites bem definidos e geralmente localiza-
Tabela 5 - Dermo-hipodermites bacterianas agudas não necrotizantes (DHBANN) - diagnóstico diferencial

\begin{tabular}{ll}
\hline Patologias infeciosas & Patologias não infeciosas \\
\hline Fasceíte necrosante & Trombose venosa profunda \\
Osteomielite & Síndrome de compartimento \\
Bursite & Intolerância próteses ortopédicas \\
Miosite & Celulite de Wells \\
Herpes Zoster (Zona) & Síndrome de Sweet \\
& Febre mediterrânica familiar \\
& Carcinomas inflamatórios \\
& Dermite de contacto \\
\hline
\end{tabular}

da num membro inferior, entre as 12 e as 14 horas subsequentes (Fig. 1). A lesão cutânea é habitualmente única, e estende-se de forma centrífuga atingindo, em média, 10 a $15 \mathrm{~cm}$ no seu maior eixo. Podem desenvolver-se vesículas e bolhas de conteúdo translúcido, geralmente flácidas, e, por vezes, com dimensões significativas (erisipela bolhosa, que ocorre em cerca de $5 \%$ dos casos) - Fig. 2. ${ }^{29,30}$ Uma discreta púrpura petequial pode ser observada, mas sem necrose, e, mais raramente, pústulas. A existência de adenopatia dolorosa e linfangite ipsilaterais, embora inconstantes, favorecem o diagnóstico. ${ }^{2,20,31}$ Está também descrita uma variante clínica de erisipela dos membros inferiores - erisipela hemorrágica - caracterizada pela presença de intenso eritema, aspeto equimótico acentuado e bolhas hemorrágicas. ${ }^{32,33}$ Outras formas de apresentação de DHBANN podem ocorrer (DHBANN atípica).

A lista de diagnósticos diferenciais de um quadro das DHBANN é extensa e inclui patologias infeciosas e não infeciosas (Tabela 5). A incerteza diagnóstica é bastante frequente, conduzindo a internamento e administração desnecessária de antibioterapia. Num estudo americano recente, $31 \%$ dos doentes admitidos no serviço de urgência diagnosticados com DHBANN do membro inferior estavam mal diagnosticados, e 92\% iniciou antibioterapia desnecessariamente. ${ }^{34}$ Do ponto de vista prático, são essencialmente três os diagnósticos diferenciais a considerar durante a avaliação inicial destes doentes: a fasceíte necrotizante e a trombose venosa profunda, pelas suas importantes implicações terapêuticas, e a dermite de contacto, dada a sua elevada incidência na população geral.

\section{Fasceíte necrotizante (FN)}

Trata-se de uma infeção rara, mas letal em cerca de $30 \%$ dos casos. É rapidamente progressiva, com envolvimento de estruturas profundas, constituindo uma urgência médica com necessidade de reconhecimento precoce e abordagem cirúrgica. Caracteriza-se pela existência de necrose da hipoderme, presença de trombose vascular, necrose da aponevrose superficial (fasceíte) e secundariamente necrose da derme (Fig. 3). O estreptococo do grupo A é o agente mais frequentemente implicado, mas não é rara a presença de uma flora polimicrobiana ( $S$. aureus, anaeróbios, enterobactérias). ${ }^{20,22,35}$

A nível cutâneo, assemelha-se a uma apresentação atípica de DHBANN, havendo também casos em que a superfície cutânea está inicialmente poupada. O sintoma- 


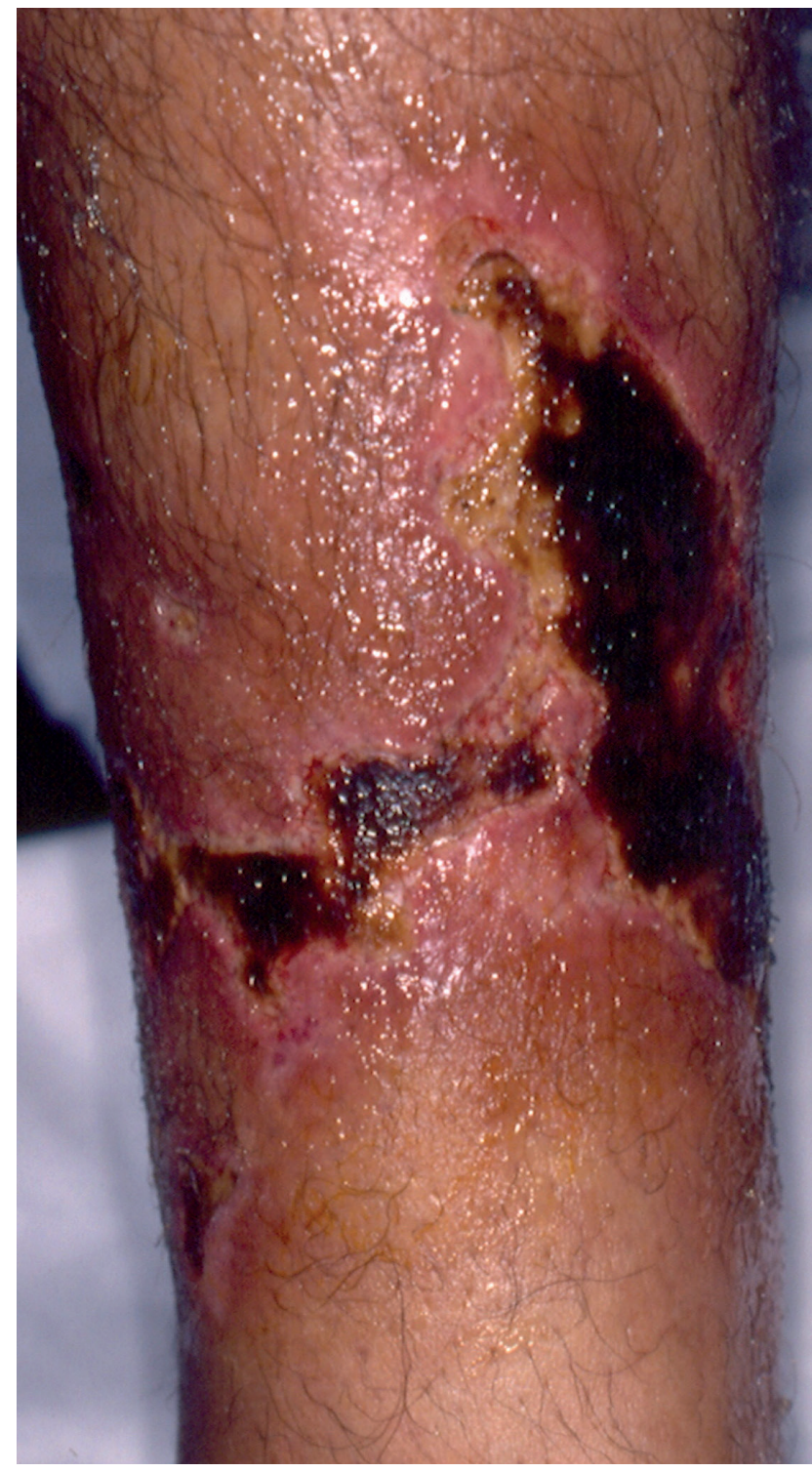

Figura 3 - Fasceíte necrosante do membro inferior (aspeto de necrose)

-chave que deve levantar a suspeita clínica, e está presente inicialmente, é a dor num grau desproporcional aos achados clínicos, e que ultrapassa os limites da lesão. O estado geral do doente é com frequência afetado, com evolução para disfunção de órgãos-alvo. Com a evolução do quadro clínico, poderão surgir necrose cutânea, formação de boIhas, hipostesia e crepitação.

A maioria dos casos associa-se a, pelo menos, um dos seguintes fatores de risco: imunossupressão, utilização de drogas injetáveis, cirurgia ou trauma recente, diabetes, úlcera sobre-infectada do pé, doença arterial periférica, desnutrição, alcoolismo. ${ }^{36}$

O diagnóstico diferencial entre DHBANN e fasceíte necrotizante (Tabela 6) é crucial, já que a realização de desbridamento cirúrgico em tempo útil é essencial em termos de prognóstico. Wong $\mathrm{CH}$ et al propõem a utilização de uma pontuação, baseada em indicadores laboratoriais de risco (proteína C reativa, contagem de leucócitos, hemoglobina, natremia, creatininemia e glicemia) para facilitar o diagnóstico de $\mathrm{FN}$, com um valor máximo de 13. Um valor igual ou superior a seis seria suspeito de FN, e igual ou superior a oito, fortemente preditor. (Tabela 7). Outros autores propõem esquemas mais simplificados, incluindo apenas a leucocitose e a hiponatremia. Porém, estes esquemas de pontuação, exclusivamente laboratoriais, não entram em linha de conta com outros dados de natureza clínica e imagiológicos, importantes na decisão diagnóstica. ${ }^{77-39}$

\section{Trombose venosa profunda (TVP)}

Dentro das patologias não infeciosas, a trombose venosa profunda é o diagnóstico diferencial mais frequentemente evocado. ${ }^{31} \mathrm{~A}$ presença de febre elevada, associada a placa eritematosa de limites bem definidos, característicos da erisipela, contrasta geralmente com o aspeto pouco inflamatório da TVP (phlegmasia alba dolens) (Fig. 4); a presença de linfangite e adenopatia associadas é também menos frequente (Tabela 8 ).

\section{Dermatite de contacto (DC)}

A dermatite de contacto é uma patologia inflamatória cutânea comum que resulta do contacto da pele com um agente físico ou químico. Divide-se em DC irritativa $(80 \%$ dos casos) e DC alérgica. A primeira resulta da ativação do sistema imunitário inato pelo efeito citotóxico direto, enquanto que a segunda resulta de uma reação de hipersensibilidade retardada mediada por células $T$ após contacto com o alergéneo. ${ }^{31}$

Surge geralmente como complicação da aplicação de medicamentos tópicos (antissépticos ou antimicrobianos) no contexto do tratamento de feridas traumáticas ou úlceras crónicas, e caracteriza-se, na fase aguda, pela presença no local de aplicação de prurido intenso e lesões cutâneas eritemato-vesico-exsudativas (Fig. 5).40 No diagnóstico diferencial entre dermatite de contacto e DHBANN é particularmente relevante a história clínica sugestiva, com

Tabela 6 - Dermo-hipodermites bacterianas agudas não necrotizantes (DHBANN) versus fasceíte necrotizante

\begin{tabular}{ll}
\hline DHBANN típica & Fasceíte necrotizante \\
\hline Início súbito (febre, arrepios) & Igual \\
Bom estado geral & Atingimento do estado geral \\
Lesões com bordos bem definidos & Lesões mal delimitadas \\
Dor & Inicialmente: Dor desproporcional aos achados cutâneos e que \\
& ultrapassa os limites da lesão; Tardio: Hipoestesia \\
Estase linfática e linfangite & Necrose e tromboses venosas \\
Antibioterapia & Antibioterapia e Cirurgia \\
Mortalidade $0,5 \%$ & Mortalidade $30,0 \%$ \\
\hline
\end{tabular}


Tabela 7 - SCORE de risco de fasceíte necrotizante ${ }^{43}$

\begin{tabular}{lll}
\hline Dados analíticos & Valores & Pontuação \\
\hline Proteína C reactiva $(\mathrm{mg} / \mathrm{dL})$ & $<15 \mathrm{mg} / \mathrm{dL}$ & 0 \\
& $>15 \mathrm{mg} / \mathrm{dL}$ & +4 \\
Leucócitos $(\times 10000 / \mathrm{uL})$ & $<15$ & 0 \\
& $15-25$ & +1 \\
& $>25$ & +2 \\
Hemoglobina $(\mathrm{g} / \mathrm{dL})$ & $>13,5$ & 0 \\
& $11-13,5$ & +1 \\
Sódio $(\mathrm{mEq} / \mathrm{L})$ & $<11$ & +2 \\
& $>135$ & 0 \\
Creatinina $(\mathrm{mg} / \mathrm{dL})$ & $<135$ & +2 \\
& $<1.6$ & 0 \\
Glicose $(\mathrm{mg} / \mathrm{dL})$ & $>1.6$ & +2 \\
& $>180$ & 0 \\
& $<180$ & +1 \\
\hline
\end{tabular}

Tabela 8 - Dermo-hipodermites bacterianas agudas não necrotizantes (DHBANN) versus trombose venosa profunda

\begin{tabular}{lll}
\hline & DHBANN típica & Trombose venosa profunda \\
\hline Temperatura & Quente & Normal ou fria \\
Cor & Eritema & Normal ou cianótica \\
Superfície & 'Pele de laranja' & Lisa \\
Adenopatia & Frequente & Ausente \\
Linfangite & Frequente & Ausente \\
\hline
\end{tabular}

o aparecimento das lesões no local de aplicação de um tópico suspeito. Por vezes as duas patologias coexistem, pelo que são necessários testes epicutâneos para o diagnóstico definitivo de dermatite de contacto alérgica.

As demais entidades incluídas no diagnóstico diferencial de DHBANN devem ser equacionadas num quadro de resposta insatisfatória à terapêutica antibiótica inicial e, em alguns casos, quando na presença de contexto clínico específico.

\section{DIAGNÓSTICO}

O diagnóstico de uma DHBANN é geralmente fácil e essencialmente clínico. Os parâmetros clínicos e analíticos considerados encontram-se resumidos na Tabela 9. Nos casos em que a apresentação inicial é típica, e na ausência de comorbilidades, a avaliação diagnóstica adicional é desnecessária e o doente pode ser tratado em regime de ambulatório. ${ }^{2,41}$

Perante um quadro de DHBANN com atingimento sistémico (febre, hipotensão, taquicardia), é importante a realização de hemoculturas, hemograma e bioquímica (função renal e ionograma, creatina fosfocinase, proteína $C$ reativa e lactato) para diagnosticar disfunções orgânicas e considerar os diagnósticos diferenciais. A presença de leucocitose importante, hiponatremia e elevação da creatina fosfocinase, aumenta o risco de fasceíte necrotizante.

\section{Exames bacteriológicos}

O papel dos exames bacteriológicos é muito limitado. Para além de uma sensibilidade baixa, estes métodos colo-

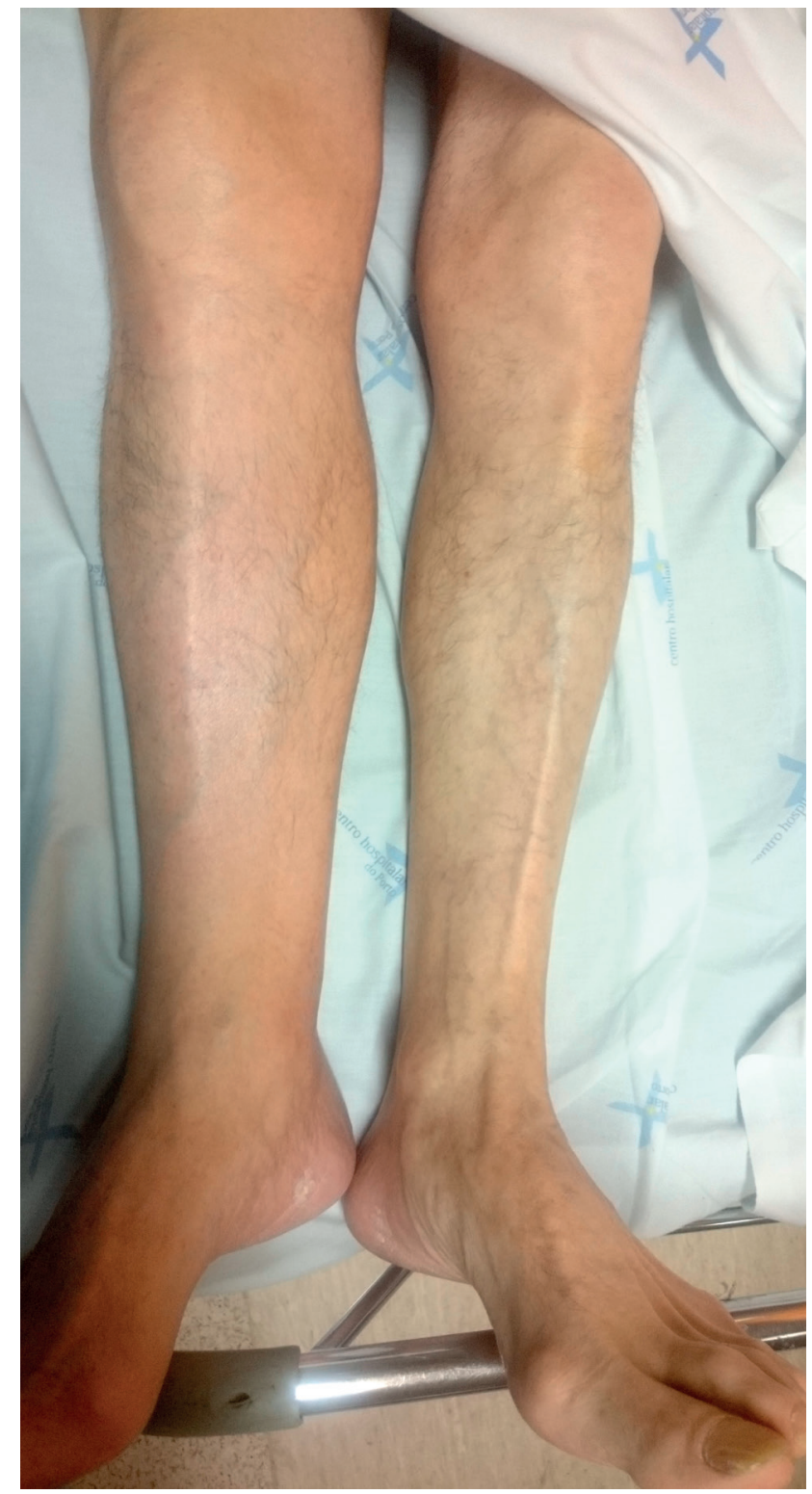

Figura 4 - Trombose venosa profunda do membro inferior direito

cam também problemas de interpretação, dada a possibilidade de contaminação por flora comensal e, de uma forma geral, não são indicados. ${ }^{10,11}$

As hemoculturas, se positivas, definem o agente etiológico, porém a incidência de bacteriemia é relativamente baixa $(2 \%$ a $18,5 \%),{ }^{42}$ o que explica que somente em $5 \%$ dos casos as hemoculturas sejam positivas. ${ }^{10,20,43}$ Podem ser úteis quando o risco de bacteriemia é elevado (tal como na sépsis ou nos casos secundários a linfedema), ${ }^{44}$ assim como em doentes com neoplasia sob quimioterapia, neutropenia, imunodeficiência mediada por células grave, história de contacto com água ou mordeduras animais na origem do processo infecioso.

A serologia estreptocócica, que deve incluir a determinação seriada dos títulos de anti-estreptolisina $\mathrm{O}$ e anti-desoxiribonuclease $\mathrm{B}$, com 10 a 15 dias de intervalo para garantir a sua especificidade, só permite um diagnóstico retrospetivo. ${ }^{45}$ 


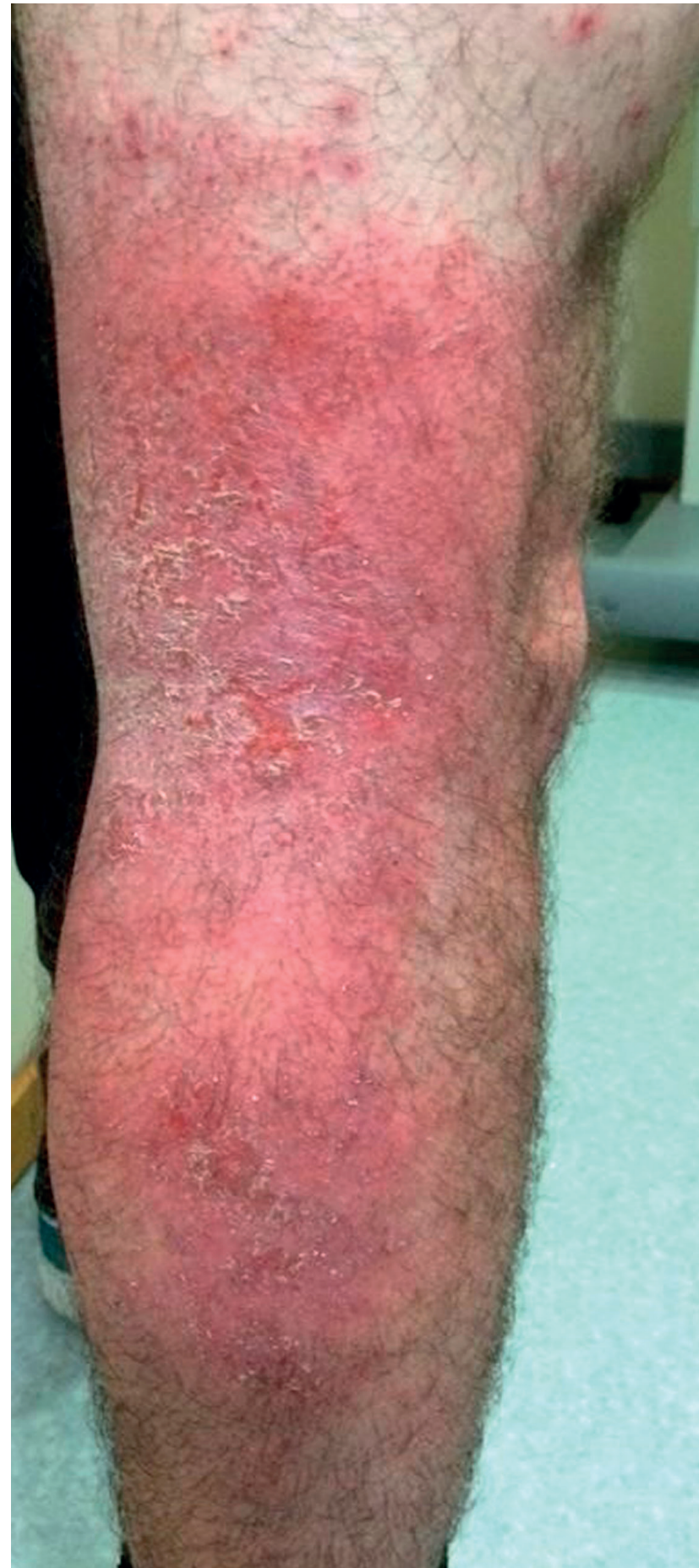

Figura 5 - Eczema de contacto do membro inferior direito

A cultura das amostras de pele afetada pode ser obtida por aspiração de bolhas, aspiração por agulha após injeção de soro fisiológico, ou por biópsia cutânea. As amostras de aspirados por agulha são positivas em apenas $10 \%$ dos casos, não estando indicadas. ${ }^{46}$ As culturas de amostras de pele obtidas por biópsia são positivas em cerca de $20 \%$ a $33 \%$. $^{13,47,48}$

Para além das técnicas de microbiologia clássicas, a pesquisa de antigénios por imunofluorescência direta, ${ }^{49}$ ou pela técnica de aglutinação em látex, ${ }^{50}$ a partir de amostras
Tabela 9 - Dermo-hipodermites bacterianas agudas não necrotizantes (DHBANN) - critérios de diagnóstico

Início súbito

Febre $\left(\geq 38^{\circ} \mathrm{C}\right)$, arrepios, mal-estar

Placa eritematosa, edematosa, dolorosa e de limites bem definidos

Ausência de necrose

Adenopatia e/ou linfangite

Estado geral conservado

Leucocitose com neutrofilia

Hemoculturas positivas

de pele permite aumentar esta sensibilidade, embora não sejam utilizadas na prática clínica.

\section{Hemograma e marcadores de fase aguda}

A presença de leucocitose neutrofílica (geralmente entre 13000 - 15000 leucócitos/ $\mu$ l) é o único exame biológico não bacteriológico considerado como critério diagnóstico da erisipela; no entanto, está ausente em cerca de metade dos casos. ${ }^{31,51,52}$

O aumento significativo da velocidade de sedimentação e da proteína $C$ reativa são frequentes mas desprovidos de especificidade..$^{51,52}$

A procalcitonina é uma hormona peptídica secretada por células parenquimatosas não-neuroendócrinas, com níveis séricos tipicamente inferiores a $0,05 \mathrm{ng} / \mathrm{mL}$ num indivíduo saudável e níveis que podem atingir os 50 a $800 \mathrm{ng} /$ $\mathrm{mL}$ em doentes com sépsis grave por infeção bacteriana. ${ }^{53}$ Vários estudos demonstram que o valor da procalcitonina está aumentado na fasceíte necrotizante, ao contrário das DHBANN, onde permanece baixo. Parece, por isso, promissora para auxiliar no diagnóstico diferencial entre DHBANN e fasceíte necrotizante. Após o desbridamento cirúrgico nesta última patologia, pode também predizer a erradicação cirúrgica dos focos infeciosos, estando o seu doseamento recomendado um a dois dias após o procedimento cirúrgico. ${ }^{54-57}$

\section{Exame histopatológico de pele}

A realização de uma biópsia cutânea para análise histológica não está indicada no contexto da investigação diagnóstica de uma DHBANN. Em primeiro lugar, carece de especificidade, mostrando uma inflamação neutrofílica intensa da derme e, em menor grau, da hipoderme com envolvimento linfático. É rara a observação dos agentes patogénicos. ${ }^{58}$ Por outro lado, a realização desta técnica invasiva acarreta um risco iatrogénico não desprezível em face da possibilidade de ulceração secundária em área de pele já severamente afetada. Pode ser importante apenas para o diagnóstico diferencial com outras dermatoses, podendo justificar-se nos casos atípicos e com resposta inadequada à antibioterapia.

\section{Imagiologia}

Os exames imagiológicos podem ter um papel para 
avaliação de complicações ou no diagnóstico diferencial.

Nos casos de apresentação atípica, em que se considere o diagnóstico diferencial com a TVP, pode ser útil realizar ecodoppler venoso dos membros inferiores. O risco de TVP é baixo em doentes hospitalizados por DHBANN e, na ausência de suspeita clínica documentada, não está indicada a sua pesquisa sistemática através deste exame. ${ }^{31,59}$

A ecografia é uma técnica imagiológica adequada para identificar abcessos ocultos, com um estudo a demonstrar que os achados ecográficos alteraram a abordagem terapêutica em $50 \%$ dos doentes diagnosticados com abcesso (uma vez que o ponto-chave na abordagem é, nestes casos, a incisão e drenagem). ${ }^{60}$ Num estádio inicial da infeção, e nos casos em que estão presentes à admissão sinais e sintomas de elevada suspeição clínica de FN (tais como necrose e hipostesia), a ecografia tem vindo a provar a sua utilidade ao identificar alterações altamente sugestivas, nomeadamente espessamento do tecido subcutâneo e acumulação de fluído ao nível da fáscia por mais de 4 $\mathrm{mm}$, com ou sem a presença da 'cauda de cometa' do gás em tecidos infetados. ${ }^{61}$

A ressonância magnética (RM) também constitui uma boa opção, por permitir a identificação de alterações ao nível do tecido adiposo da hipoderme e fáscias musculares profundas (coleções líquidas, espessamento e captação de contraste), embora na prática clínica raramente se encontre disponível de forma imediata. ${ }^{22,62}$

Importa salientar que a realização de um estudo imagiológico não deve atrasar a atitude cirúrgica, que é fundamental quando a probabilidade de FN é elevada.

\section{Testes epicutâneos}

A realização de provas epicutâneas pode justificar-se nos casos em que se verifica aplicação prévia de tópicos, existência de prurido e/ou resposta insatisfatória à antibioterapia. A associação de uma DC é frequente no contexto das infeções cutâneas, devido à comercialização de diversos produtos com elevado potencial sensibilizante e aos marcados hábitos de auto-medicação da nossa população. Estes testes devem ser efetuados após a fase aguda, utilizando alergéneos padronizados e os medicamentos suspeitos.

\section{TERAPÊUTICA}

$\mathrm{Na}$ ausência de complicações,o tratamento das DHBANN é exclusivamente médico e consiste, no essencial, na instituição de antibioterapia empírica tendo em conta a epidemiologia conhecida desta infeção. ${ }^{41}$ Adicionalmente, devem ser implementadas medidas de carácter geral (repouso com elevação do membro afetado, punção de bolhas sem retirar o teto, de forma a acelerar a re-epitelização, evitar a utilização de anti-sépticos com potencial sensibilizante e de pensos compressivos). A utilização de anti-microbianos tópicos (ácido fusídico a $2 \%$, mupirocina $20 \mathrm{mg} / \mathrm{g}$ ou sulfadiazina argêntica a 1\%) pode ser útil nas formas bolhosas. ${ }^{63}$

A avaliação da necessidade de hospitalização constitui um importante passo na delineação da abordagem terapêutica (Tabela 10). O internamento deve ser considerado em doentes com sinais de gravidade locais ou sistémicos, imunossupressão, exacerbação de comorbilidades, ausência de via oral, incapacidade de cumprimento terapêutico, ausência de resposta após 48 a 72 horas de antibioterapia adequada. ${ }^{64}$

\section{Antibioterapia}

O agente etiológico mais frequente das DHBANN é, sem dúvida, o Streptococcus pyogenes (grupo A), com alguns casos a poderem ser causados por estreptococos grupo $G$ e grupo D ou Staphylococcus aureus. Sabe-se que a maioria dos doentes responde ao tratamento com penicilina, ${ }^{65}$ apesar deste antibiótico não cobrir Staphylococcus aureus meticilino-sensíveis (MSSA). Contudo, a maioria dos clínicos seleciona antibioterapias empíricas com cobertura de MSSA, uma vez que poderão ser o agente etiológico em cerca de $15 \%$ dos casos. ${ }^{66,67}$ A flucloxacilina e as cefalosporinas de primeira geração deverão ser a primeira opção terapêutica, já que permitem a cobertura de estreptococos e MSSA, o que evita um espectro demasiado alargado. ${ }^{46}$ Perante uma DHBANN típica sem critérios de internamento, a primeira opção terapêutica é a instituição empírica de flucloxacilina $500 \mathrm{mg}$ oral de seis em seis horas. ${ }^{68} \mathrm{~A}$ cefradina oral é uma alternativa. Nos doentes alérgicos à penicilina, a claritromicina ou a clindamicina poderão ser utilizadas. 20,22,41 Geralmente, um curso de sete dias é suficiente para a resolução da infeção. ${ }^{68}$ Após a instituição da antibioterapia espera-se uma rápida resolução da febre

Tabela 10 - Dermo-hipodermites bacterianas agudas não necrotizantes (DHBANN) - critérios de internamento

Idade superior a 60 anos

Localização facial

Sinais de gravidade:

locais (bolhas, púrpura, necrose, hipostesia)

gerais (confusão, agitação, oligúria, hipotensão)

Fatores de comorbilidade: imunodepressão, neutropenia, asplenia, cirrose, insuficiência cardíaca ou renal

Ausência de via oral

Terapêutica em ambulatório ineficaz (após 48 a 72 horas)

Incapacidade de cumprimento terapêutico 
Tabela 11 - Dermo-hipodermites bacterianas agudas não necrotizantes (DHBANN) - antibioterapia

\begin{tabular}{|c|c|}
\hline Ambulatório & Internamento \\
\hline $\begin{array}{l}\text { Flucloxacilina } 500 \mathrm{mg} 6 / 6 \text { horas PO } \\
\text { Cefradina } 500 \mathrm{mg} 6 / 6 \text { horas PO } \\
\text { Amoxicilina/ácido clavulânico } 875 \mathrm{mg}+125 \mathrm{mg} 12 / 12 \text { horas PO } \\
\text { Clindamicina } 300 \mathrm{mg} 6 / 6 \text { horas PO } \\
\text { Ciprofloxacina } 750 \mathrm{mg} 12 / 12 \text { horas PO* }\end{array}$ & $\begin{array}{l}\text { Flucloxacilina } 2 \mathrm{~g} 6 / 6 \text { horas IV } \\
\text { Cefazolina } 1 \mathrm{~g} 6 / 6 \text { horas IV } \\
\text { Amoxicilina/ácido clavulânico } 1000 \mathrm{mg}+100 \mathrm{mg} 12 / 12 \text { horas IV } \\
\text { Imipenem } 1 \text { - } 2 \mathrm{~g} 8 / 8 \text { horas IV* } \\
\text { MRSA } \\
\text { Vancomicina } 1 \text { - } 2 \mathrm{~g} / \text { dia IV } \\
\text { Linezolido }\end{array}$ \\
\hline $\begin{array}{l}\text { Alergia a penicilina } \\
\text { Claritromicina } 500 \mathrm{mg} 12 / 12 \text { horas PO } \\
\text { Clindamicina } 600 \mathrm{mg} 8 / 8 \text { horas PO }\end{array}$ & $\begin{array}{l}\text { Alergia a penicilina } \\
\text { Claritromicina } 500 \mathrm{mg} 12 / 12 \text { horas IV } \\
\text { Clindamicina } 900 \mathrm{mg} 8 / 8 \text { horas IV }\end{array}$ \\
\hline
\end{tabular}

* Se suspeita de agentes mistos (p.e. diabéticos)

(24 - 48 horas) e diminuição da dor. A resolução dos achados cutâneos é mais lenta, ainda que não seja esperada uma expansão das dimensões da lesão sob antibioterapia. $\mathrm{Na}$ ausência de resposta às 48 horas (febre, aumento da dor, expansão da lesão), o doente deverá ser observado novamente para exclusão de complicação precoce (abcesso) ou alteração de antibioterapia. ${ }^{68}$

A cobertura empírica de Staphylococcus aureus meticilino-resistentes (MRSA) apenas deve ser considerada nos casos de ferida traumática, e em doentes com antecedentes de infeção por MRSA ou utilizadores de drogas intravenosas injetáveis. ${ }^{68}$ A cobertura oral de MRSA é conseguida adicionando cotrimoxazol ou doxiciclina ao beta-lactâmico, ou com a alteração para clindamicina. ${ }^{46}$

Nos casos de DHBANN com critérios de internamento está indicada a antibioterapia intravenosa, e as primeiras opções terapêuticas são a flucloxacilina ou a cefazolina. Nos doentes alérgicos à penicilina, a claritromicina ou a clindamicina são, mais uma vez, as opções terapêuticas.

Em ambiente nosocomial e forte suspeita de infeção MRSA, a vancomicina é a escolha indicada, sendo o linezolido uma alternativa.

Nas DHBANN atípicas de provável etiologia polimicrobiana, como nos casos do pé diabético, pode justificar-se a associação de antibióticos ou a utilização de fármacos com espectro mais alargado. ${ }^{22}$

Os diferentes antibióticos e doses aconselhadas encontram-se resumidos na Tabela 11.

\section{Anti-inflamatórios não esteroides (AINE) e corticoste- róides}

Com base em estudos clínicos retrospetivos, ${ }^{69,70}$ diversas publicações sugerem, nos últimos anos, uma ligação potencial entre o tratamento de uma erisipela com AINE e a evolução para fasceíte necrotizante. As possíveis explicações para este fenómeno são a possibilidade de atenuação dos sinais e sintomas clínicos, o que retarda o momento do diagnóstico e de interferência com os mecanismos moleculares de combate à infeção (inibição das funções granulocitárias e aumento da produção de citoquinas). No entanto, nenhum estudo permitiu, até à data, estabelecer uma relação causa-efeito definitiva. Deste modo, parece ser mais prudente evitar o uso destes fármacos no contexto das DHBANN. Nos casos de febre de difícil controlo ou queixas álgicas intensas, o paracetamol é uma alternativa adequada.

Pelo mesmo receio associado à utilização dos AINEs, o uso de corticosteróides não está indicado no tratamento da erisipela, excetuando na forma particular de erisipela hemorrágica. Nesta forma, por vezes existe apenas uma resposta parcial após instituição de antibioterapia adequada, com observações clínicas ${ }^{33}$ a demonstrarem o benefício de corticoterapia sistémica em esquema adjuvante (prednisona $0,5 \mathrm{mg} / \mathrm{kg} / \mathrm{dia}$ com redução rápida num total de oito dias).

\section{Anticoagulantes}

Tendo em conta o baixo risco de ocorrência de TVP $(4,9 \%)$, o uso sistemático de anti-coagulação profilática não está indicado no tratamento da erisipela. Somente a existência de contexto clínico que condicione um risco trombo-embólico moderado a alto justificam a sua utilização. ${ }^{59}$

\section{COMPLICAÇÕES}

Com a instituição de terapêutica adequada, a evolução de uma DHBANN típica é geralmente favorável (80\%), com apirexia nas 48 a 72 horas após o início da antibioterapia, seguida pela melhoria progressiva dos sinais locais e resolução completa em duas semanas. Nas formas de erisipela bolhosa, a evolução é geralmente mais lenta, sendo necessários, em média, 20 dias, para a completa re-epitelização

Tabela 12 - Dermo-hipodermites bacterianas agudas não necrotizantes (DHBANN) - complicações

\begin{tabular}{ll}
\hline Precoces & Tardias \\
\hline Locais & Recidiva \\
Abcesso e/ou necrose & Linfedema crónico \\
Trombose venosa profunda & \\
Gerais & \\
Bacteriemia/Septicemia & \\
Toxidermia & \\
Descompensação de doença crónica & \\
Morte & \\
\hline
\end{tabular}


ser atingida. ${ }^{71}$

As complicações dividem-se em precoces, observadas à data do diagnóstico ou nos primeiros dias de hospitalização, e tardias, do tipo recidiva ou sequelas (Tabela 12).

As complicações precoces são raras, e a nível local destacam-se o abcesso e/ou necrose (3\% - 12\%), cujo reconhecimento é importante por requerer frequentemente tratamento cirúrgico, e a TVP que, embora rara $(2 \%$ - $7,8 \%)$, deve ser considerada quando a resposta à antibioterapia não for favorável. Entre as complicações de carácter geral são de referir a toxidermia (5\%), a bacteriemia/septicemia $(2 \%)$ e o agravamento de doenças associadas $(0,6 \%)$, nomeadamente: diabetes mellitus, insuficiência renal ou cardíaca. ${ }^{2,71}$ A taxa de mortalidade é de $0,5 \%$ e, na grande maioria dos casos, resulta da descompensação irreversível de patologias crónicas do doente. ${ }^{71}$

As recidivas representam a complicação tardia mais frequente (cerca de $30 \%$ aos três anos), ${ }^{80}$ sendo responsáveis pela elevada taxa de morbilidade. Alguns estudos apontam como fatores responsáveis a persistência do intertrigo interdigital, o linfedema crónico, a presença de agente que não o estreptococo do grupo A e a terapêutica antibiótica insuficiente. $^{72}$

O linfedema crónico é também uma complicação frequente, afetando um em 10 doentes hospitalizados com DHBANN do membro inferior. ${ }^{73}$

\section{PREVENÇÃO}

As DHBANN são uma infeção bacteriana com prognóstico imediato extremamente favorável, fazendo com que a principal preocupação na abordagem resida no efetivo controlo e tratamento dos fatores que condicionam a sua elevada taxa de recidivas (prevenção primária).

Em primeiro lugar, deve assegurar-se o rigoroso cumprimento do tratamento, estimando-se que a insuficiente duração da antibioterapia seja responsável pela recidiva em $65 \%$ dos casos. ${ }^{71}$

A redução de peso, o tratamento adequado das patologias cardiovasculares que condicionam linfedema crónico (insuficiência cardíaca congestiva, insuficiência venosa crónica, etc.) e a identificação e tratamento adequado de soluções de continuidade na pele constituem as medidas a considerar, de acordo com cada caso específico.

A correta abordagem terapêutica do intertrigo interdigital de etiologia fúngica, infeção com elevada prevalência na população geral, assume particular importância, uma vez que a sua erradicação permitiria evitar cerca de $60 \%$ das erisipelas. ${ }^{27} \mathrm{Na}$ grande maioria dos casos, a etiologia é dermatofítica e o seu tratamento inclui medidas de higiene (secagem das pregas interdigitais, uso de calçado arejado e meias de algodão), eliminação dos reservatórios de dermatófitos (tratamento de onicomicose) e tratamento antifúngico tópico ou sistémico. 2,22,27

Uma meta-análise recente demonstrou que, em doentes com dois ou mais episódios de DHBANN do membro inferior, a instituição de antibioterapia profilática (penicilina benzatínica 2.4 UM ou 1.2 UM de 4/4 semanas por via intramuscular; alternativamente, eritromicina $250 \mathrm{mg} / \mathrm{dia}$ em casos de alergia à penicilina) diminui em $70 \%$ o risco de recidiva durante a duração do tratamento. ${ }^{74} \mathrm{~A}$ profilaxia deve ser prolongada, dado que o seu efeito é unicamente supressivo. ${ }^{74}$ Todavia, doentes com um índice de massa corporal de 33 ou mais, elevado e com história de múltiplas recidivas ou linfedema, demonstram pior resposta ao tratamento profilático. ${ }^{75}$

\section{CONCLUSÃO}

As DHBANN constituem uma patologia comum, com um diagnóstico sobretudo clínico (com base na história e exame físico) e, na maioria dos casos, o tratamento é realizado em ambulatório com evolução favorável. Contudo, no seu diagnóstico diferencial incluem-se entidades associadas a morbilidade e mortalidade importantes, nomeadamente TVP e FN. Os agentes etiológicos das DHBANN são geralmente previsíveis, permitindo a escolha de uma antibioterapia empírica de espectro estreito, o que possibilita minimizar tanto os efeitos secundários como o desenvolvimento de resistência aos antimicrobianos. Sendo a recidiva relativamente frequente, a profilaxia antibiótica prolongada deverá ser instituída em determinados tipos de doentes.

\section{PROTEÇÃO DE PESSOAS E ANIMAIS}

Os autores declaram que os procedimentos seguidos estavam de acordo com os regulamentos estabelecidos pelos responsáveis da Comissão de Investigação Clínica e Ética e de acordo com a Declaração de Helsínquia da Associação Médica Mundial atualizada em 2013.

\section{CONFIDENCIALIDADE DOS DADOS}

Os autores declaram ter seguido os protocolos do seu centro de trabalho acerca da publicação de dados.

\section{CONSENTIMENTO INFORMADO}

Obtido.

\section{CONFLITOS DE INTERESSE}

Os autores declaram não ter qualquer conflito de interesse relativamente ao presente artigo.

\section{FONTES DE FINANCIAMENTO}

Não foi utilizada nenhuma bolsa ou subsídio para a realização do trabalho.

\section{REFERÊNCIAS}

1. Grosshans E. Erysipelas. Clinicopathological classification and terminology. Ann Dermatol Venereol. 2001;128:307-11.

2. Bonnetblanc JM, Bédane C. Erysipelas. Am J Clin Dermatol.

. Gunderson CG, Martinello RA. A systematic review of bacteremias in cellulitis and erysipelas. J Infect. 2012;64:148-55. 
4. Bläckberg A, Trell K, Rasmussen M. Erysipelas, a large retrospective study of aetiology and clinical presentation. BMC Infect Dis. 2015;15:402.

5. Bruun T, Oppegaard O, Kittang BR, Mylvaganam H, Langeland $\mathrm{N}$, Skrede S. Etiology of cellulitis and clinical prediction of streptococcal disease: a prospective study. Open Forum Infect Dis. 2016;3:ofv181.

6. Stevens DL, Bisno AL, Chambers HF, Dellinger EP, Goldstein EJ, Gorbach SL, et al. Practice guidelines for the diagnosis and management of skin and soft tissue infections: 2014 update by the Infectious Diseases Society of America. Clin Infect Dis. 2014;59:e10-52.

7. Weng QY, Raff AB, Cohen JM, Gunasekera N, Okhovat JP, Vedak P, et al. Costs and consequences associated with misdiagnosed lower extremity cellulitis. JAMA Dermatol. 2017;153:141.

8. Ellis Simonsen SM, Van Orman ER, Hatch BE, Jones SS, Gren LH, Hegmann KT, et al. Cellulitis incidence in a defined population. Epidemiol Infect 2006;134:293-9.

9. Simon MS, Cody RL. Cellulitis after axillary lymph node dissection for carcinoma of the breast. Am J Med. 1992;93:543-8.

10. Denis F, Martin C, Ploy MC. L'érysipèle: données microbiologiques et pathogéniques. Ann Dermatol Venereol. 2001;128:317-25.

11. Sachs MK. The optimum use of needle aspiration in the bacteriologic diagnosis of cellulitis in adults. Arch Intern Med. 1990;150:1907-12.

12. Sachs MK. Cutaneous cellulitis. Arch Dermatol. 1991;127:493-6.

13. Eriksson B, Jorup-Rönström C, Karkkonen K, Sjöblom AC, Holm SE. Erysipelas: clinical and bacteriologic spectrum and serological aspects. Clin Infect Dis. 1996;23:1091-8.

14. Jorup-Rönström C. Epidemiological, bacteriological and complicating features of erysipelas. Scand J Infect Dis. 1986;18:519-24.

15. Siljander T, Karppelin M, Vahakuopus S, Syrjanen J, Toropainen $\mathrm{M}$, Kere $\mathrm{J}$, et al. Acute bacterial, nonnecrotizing cellulitis in Finland: microbiological findings. Clin Infect Dis. 2008;46:855-61.

16. Bernard P. Streptococcal cause of erysipelas and cellulitis in adults. Arch Dermatol. 1989;125:779.

17. Bowler PG, Duerden BI, Armstrong DG. Wound microbiology and associated approaches to wound management. Clin Microbiol Ver. 2001;14:244-69.

18. Eron LJ. Managing skin and soft tissue infections: expert panel recommendations on key decision points. J Antimicrob Chemother. 2003;52:3i-17.

19. Carratalà J, Rosón B, Fernández-Sabé N, Shaw E, del Rio O, Rivera $A$, et al. Factors associated with complications and mortality in adult patients hospitalized for infectious cellulitis. Eur J Clin Microbiol Infect Dis. 2003;22:151-7

20. Bisno AL, Stevens DL. Streptococcal infections of skin and soft tissues N Engl J Med. 1996;334:240-6.

21. Brook I, Frazier EH. Clinical features and aerobic and anaerobic microbiological characteristics of cellulitis. Arch Surg. 1995;130:786-92.

22. Swartz MN. Cellulitis. N Engl J Med. 2004;350:904-12.

23. Morris A. Cellulitis and erysipelas. Clin Evid. 2006;2207-11.

24. Bjornsdottir S, Gottfredsson M, Thorisdottir AS, Gunnarsson GB Rikardsdottir $\mathrm{H}$, Kristjansson $\mathrm{M}$, et al. Risk factors for acute cellulitis of the lower limb: a prospective case-control study. Clin Infect Dis 2005;41:1416-22.

25. Semel JD, Goldin H. Association of athlete's foot with cellulitis of the lower extremities: diagnostic value of bacterial cultures of ipsilateral interdigital space samples. Clin Infect Dis. 1996;23:1162-4.

26. Raff AB, Kroshinsky D. Cellulitis. JAMA 2016;316:325.

27. Dupuy A. Descriptive epidemiology and knowledge of erysipelas risk factors. Ann Dermatol Venereol. 2001;128:312-6.

28. Givner LB. Periorbital versus orbital cellulitis. Pediatr Infect Dis. J 2002;21:1157-8.

29. Vinh DC, Embil JM. Rapidly progressive soft tissue infections. Lancet Infect Dis. 2005;5:501-13

30. Edwards J. A blistering disease: bullous erysipelas. CMAJ. 2006;175:244

31. Vaillant L. Critères diagnostiques de l'érysipèle. Ann Dermatol Venereol 2001;128:326-33.

32. Estines O, Coste N, Perceau G, Becker S, Leberruyer P, Bernard P. Hemorrhagic erysipelas of the lower limbs: 5 cases. Ann Dermatol Venereol. 2004;131:833.

33. Estines O, Coste N, Perceau G, Becker S, Leberruyer P, Bernard P. Erysipèle hémorragique: intérêt d'une courte corticothérapie adjuvante (3 cas). Ann Dermatol Venereol. 2003;130:523-6.

34. Weng QY, Raff AB, Cohen JM, Gunasekera N, Okhovat JP, Vedak P, et al. Costs and consequences associated with misdiagnosed lower extremity cellulitis. JAMA Dermatol. 2017;153:141.

35. Stone DR, Gorbach SL. Necrotizing fasciitis. The changing spectrum. Dermatol Clin. 1997;15:213-20.
36. Roujeau J. Necrotizing fasciitis. Clinical criteria and risk factors. Ann Dermatol Venereol. 2001;128:376-81.

37. Wong $\mathrm{CH}$, Khin LW, Heng KS, Tan KC, Low CO. The LRINEC (Laboratory Risk Indicator for Necrotizing Fasciitis) score: a tool for distinguishing necrotizing fasciitis from other soft tissue infections. Crit Care Med. 2004;32:1535-41.

38. Wall DB, Klein SR, Black S, de Virgilio C. A simple model to help distinguish necrotizing fasciitis from nonnecrotizing soft tissue infection. J Am Coll Surg. 2000;191:227-31.

39. Barie PS. The laboratory risk indicator for necrotizing fasciitis (LRINEC) score: useful tool or paralysis by analysis? Crit Care Med. 2004;32:1618-

40. Descamps V, Lejoyeux F, Marck Y, Bouscarat F, Crickx B, Belaich S. Erysipelas-like mercury exanthem. Contact Dermatitis. 1997;36:277-8.

41. Lucht F. Quelle prise en charge pour l'érysipèle? Traitement antibiotique: molécules, voies d'administration. Ann Dermatol Venereol. 2001;128:345-7.

42. Lee GC, Hall RG, Boyd NK, Dallas SD, Du LC, Treviño LB, et al. A prospective observational cohort study in primary care practices to identify factors associated with treatment failure in Staphylococcus aureus skin and soft tissue infections. Ann Clin Microbiol Antimicrob. 2016;15:58.

43. Perl B, Gottehrer NP, Raveh D, Schlesinger Y, Rudensky B, Yinnon AM. Cost-effectiveness of blood cultures for adult patients with cellulitis. Clin Infect Dis. 1999:29:1483-8.

44. Woo PC, Lum PN, Wong SS, Cheng VC, Yuen KY. Cellulitis complicating lymphoedema. Eur J Clin Microbiol Infect Dis. 2000;19:294-7.

45. Leppard BJ, Seal DV, Colman G, Hallas G. The value of bacteriology and serology in the diagnosis of cellulitis and erysipelas. $\mathrm{Br} \mathrm{J}$ Dermatol. 1985;112:559-67.

46. ACUTE Medicine. Guidelines on the management of cellulitis in adults. CREST Clin Resour Effic Support Team (CREST)2005. [consultado $2021 \mathrm{Fev}$ 08]. Available from: https://www.rcem.ac.uk/docs/External\%20 Guidance/10n.\%20Guidelines \%20on\%20the\%20management $\% 20$ of $\% 20$ cellulitis $\% 20$ in $\% 20$ adults $\% 20$ (CREST, $\% 202005$.pdf.

47. Hook EW, Hooton TM, Horton CA, Coyle MB, Ramsey PG, Turck M. Microbiologic evaluation of cutaneous cellulitis in adults. Arch Intern Med. 1986;146:295-7.

48. Duvanel T, Auckenthaler R, Rohner P, Harms M, Saurat JH. Quantitative cultures of biopsy specimens from cutaneous cellulitis. Arch Intern Med. 1989;149:293-6.

49. Bernard P. Streptococcal cause of erysipelas and cellulitis in adults Arch Dermatol. 1989;125:779.

50. Bernard P, Toty L, Mounier M, Denis F, Bonnetblanc JM. Early detection of streptococcal group antigens in skin samples by latex particle agglutination. Arch Dermatol. 1987;123:468-70.

51. Lazzarini L, Conti E, Tositti G, Lalla F de. Erysipelas and cellulitis: clinical and microbiological spectrum in an Italian tertiary care hospital. J Infect. 2005;51:383-9.

52. Krasagakis $\mathrm{K}$, Valachis $\mathrm{A}$, Maniatakis $\mathrm{P}$, Krüger-Krasagakis $\mathrm{S}$, Samonis G, Tosca AD. Analysis of epidemiology, clinical features and management of erysipelas. Int J Dermatol. 2010;49:1012-7.

53. Saeed K, Ahmad N, Dryden M. The value of procalcitonin measurement in localized skin and skin structure infection, diabetic foot infections, septic arthritis and osteomyelitis. Expert Rev Mol Diagn. 2014;14:47-54

54. Uzzan B, Cohen R, Nicolas P, Cucherat M, Perret GY. Procalcitonin as a diagnostic test for sepsis in critically ill adults and after surgery or trauma: a systematic review and meta-analysis. Crit Care Med. 2006;34:1996-2003.

55. Zil-E-Ali A, Naqvi S, Tariq M. Procalcitonin: a powerful rescuer on surgical floors. Cureus. 2017;9: e1446.

56. Friederichs J, Hutter M, Hierholzer C, Novotny A, Friess H, Bühren V, et al. Procalcitonin ratio as a predictor of successful surgical treatment of severe necrotizing soft tissue infections. Am J Surg. 2013;206:368-73.

57. Wilson MP, Schneir AB. A case of necrotizing fasciitis with a LRINEC score of zero: clinical suspicion should trump scoring systems. J Emerg Med 2013;44:928-31.

58. Elder D. Lever's histopathology of the skin. $10^{\text {th }}$ ed. Philadelphia: Wolters Kluwer Lippincott Williams \& Wilkins; 2009

59. Perrot JL, Perrot S, Laporte Simitsidis S. Existe-t-il une place pour les anticoagulants dans le traitement de l'érysipèle? Ann Dermato Venereol. 2001;128:352-7.

60. Tayal VS, Hasan N, Norton HJ, Tomaszewski CA. The effect of softtissue ultrasound on the management of cellulitis in the emergency department. Acad Emerg Med. 2006;13:384-8.

61. Castleberg E, Jenson N, Dinh VA. Diagnosis of necrotizing faciitis with 
bedside ultrasound: the STAFF exam. West J Emerg Med. 2014;15:1113 .

62. Schmid MR, Kossmann T, Duewell S. Differentiation of necrotizing fasciitis and cellulitis using MR imaging. Am J Roentgenol. 1998;170:615-20.

63. Guberman D, Gilead LT, Zlotogorski A, Schamroth J. Bullous erysipelas: a retrospective study of 26 patients. J Am Acad Dermatol. 1999;41:7337.

64. Lane S, Johnston K, Sulham KA, Syed I, Pollack CV, Holland T, et al. Identification of patient characteristics influencing setting of care decisions for patients with acute bacterial skin and skin structure infections: results of a discrete choice experiment. Clin Ther. 2016;38:531-44.e9.

65. Jorup-Rönström C, Britton S, Gavlevik A, Gunnarsson K, Redman AC. The course, costs and complications of oral versus intravenous penicillin therapy of erysipelas. Infection. 1984;12:390-4.

66. Madaras-Kelly KJ, Remington RE, Oliphant CM, Sloan KL, Bearden DT. Efficacy of oral $\beta$-Lactam versus non- $\beta$-Lactam treatment of uncomplicated cellulitis. Am J Med. 2008;121:419-25.

67. Wells RD, Mason P, Roarty J, Dooley M. Comparison of initial antibiotic choice and treatment of cellulitis in the pre- and post-communityacquired methicillin-resistant Staphylococcus aureus eras. Am J Emerg
Med. 2009;27:436-9.

68. Hirschmann J V, Raugi GJ. Lower limb cellulitis and its mimics. J Am Acad Dermatol. 2012;67:163.e1-12.

69. Chosidow O, Saiag P, Pinquier L, Bastuji-Garin S, Revuz J, Roujeau JC. Nonsteroidal anti-inflammatory drugs in cellulitis: a cautionary note. Arch Dermatol. 1991;127:1845-6.

70. Holder EP, Moore PT, Browne BA. Nonsteroidal anti-inflammatory drugs and necrotising fasciitis. Drug Saf. 1997;17:369-73.

71. Crickx B. Erysipèle: évolution médicale sous traitement. Complications. Ann Dermatol Venereol. 2001;128:358-62.

72. Pavlotsky F, Amrani S, Trau H. Recurrent erysipelas: risk factors. J Dtsch Dermatol Ges. 2004;2:89-95.

73. Cox NH, Colver GB, Paterson WD. Management and morbidity of cellulitis of the leg. J R Soc Med. 1998;91:634-7.

74. Dalal A, Eskin-Schwartz M, Mimouni D, Ray S, Days W, Hodak E, et al. Interventions for the prevention of recurrent erysipelas and cellulitis. Cochrane Database Syst Rev. 2017;6:CD009758.

75. Thomas KS, Crook AM, Nunn AJ, Foster KA, Mason JM, Chalmers $\mathrm{JR}$, et al. Penicillin to prevent recurrent leg cellulitis. $\mathrm{N}$ Engl $\mathrm{J}$ Med. 2013;368:1695-703. 